\title{
AVALIAÇÃO DA GESTÃO COMERCIAL NAS MPEs NO SUDOESTE DO PARANÁ
}

\section{EVALUATION OF COMMERCIAL MANAGEMENT IN MPEs IN THE SOUTHWEST OF PARANÁ}

\author{
Recebido em 21.12.2018 Aprovado em 10.12.2019 \\ Avaliado pelo sistema double blind review \\ DOI: https://doi.org/10.32888/cge.v7i2.27533
}

\author{
Gabriela Buffon \\ gabrielabuffon@gmail.com \\ Doutoranda em Administração/Universidade Estadual de Santa Catarina - Florianópolis/Santa Catarina, Brasil
}

\section{Greice Morais Dalla Corte}

greice.dc@hotmail.com

Mestre em Gestão e Desenvolvimento Regional/Universidade Estadual do Oeste do Paraná - Francisco

Beltrão/Paraná, Brasil

Edson Santos Melo

edson.melo@,unioeste.br

Universidade Estadual do Oeste do Paraná - Francisco Beltrão/Paraná, Brasil

\section{Resumo}

O mercado está cada vez mais competitivo e desafiador, sendo fundamental para as empresas a utilização de estratégias para se manter em atividade e promover o seu crescimento. Diante disso, este artigo tem como objetivo principal verificar se as empresas de pequeno porte do Sudoeste do Paraná adotam ferramentas estratégicas de gestão comercial. A metodologia consistiu na aplicação de questionário, com perguntas voltadas a ações estratégicas de pré-venda, venda e pós-venda. Os resultados indicam que, no geral, há aplicabilidade de ferramentas de gestão comercial nas empresas. Porém, verificaram-se falhas por parte de algumas empresas durante a pré e pós-venda, implicando que os esforços dispendidos pelas mesmas, nessas etapas, podem não gerar os resultados esperados.

Palavras-chave: Gestão Comercial. Vendas. Micro, Pequenas e Médias Empresas.

\begin{abstract}
The market is increasingly competitive and challenging, being essential for companies to use strategies to stay active and promote their growth. Therefore, this article has as main objective to verify if the entrepreneurs of micro and small companies of the Southwest of Paraná apply strategic tools of commercial management in their companies. The methodology consisted in the application of a questionnaire, with questions focused on strategic pre-sale, sale and post-sale actions. The results indicate that, in general, there is applicability of commercial management tools in companies. However, it was verified failures by some companies during pre-sales and after-sales, implying that the efforts expended by them, in these steps may not generate the expected results.
\end{abstract}

Keywords: Commercial management. Sales. Micro, Small and Medium Enterprises. 


\section{Introdução}

No mundo empresarial contemporâneo é perceptível um cenário cada vez mais competitivo. As mudanças contínuas, devido à inserção de novas tecnologias, lançamento de inovações, mudanças comportamentais dos clientes, entre outros fatores que constantemente interferem nos negócios, tornam as atividades comerciais incertas e desafiadoras.

Diante desta realidade, a gestão comercial pode ser entendida como atividade-chave no sucesso do negócio, pois é por meio do processo de comercialização que ocorre a concretização das vendas. Desse modo, desenvolver estratégias comerciais inovadoras, eficazes e com foco no cliente pode ser essencial para a vitalidade e permanência de uma empresa no mercado. Embora, geralmente, as micro, pequenas e médias empresas (MPEs) não possuam um departamento específico para a gestão comercial, a competição acirrada do mercado pode forçá-las a desenvolverem estratégias de comercialização.

Conforme estudo do SEBRAE (2018), no Brasil há mais de 6,4 milhões de estabelecimentos comerciais, sendo que destes, $99 \%$ se enquadram em MPEs. Além disso, estas são responsáveis por aproximadamente $52 \%$ dos empregos formais no setor privado. Ainda segundo dados do referido estudo, o estado do Paraná tem 340.466 microempresas e 95.481 empresas de pequeno porte. Mais especificamente, concentrando-se na mesorregião Sudoeste Paranaense, há a atuação de aproximadamente 15 mil empresas enquadradas no porte de microempreendedor individual (MEI), microempresa e empresa de pequeno porte, optantes pelo regime tributário Simples Nacional (DATASEBRAE, 2017). A maioria dessas empresas localizadas no Sudoeste Paranaense atua em atividades do setor de transporte, comercialização de roupas e acessórios, alimentação e serviços de mecânica. Observa-se, ainda, que essa mesorregião, foco do estudo, é composta por 42 municípios, com média populacional de 14.822 habitantes por município (IBGE, 2018). Diante de tais números, corrobora-se o argumento de Costa (2016), qual seja que o empreendedorismo é necessário para o desenvolvimento da economia e da sociedade de qualquer região.

À luz do exposto, o presente artigo coloca como problema de pesquisa o seguinte questionamento: quais são as principais estratégias de gestão comercial adotadas pelas MPEs localizadas no Sudoeste do Paraná? A gestão comercial é vital para a organização, pois o relacionamento com o seu grupo de interesse (clientes, fornecedores ou concorrentes) acontece por esse departamento. Tecnicamente o processo de comercialização passa por três etapas: pré-venda, venda e pós-venda. Comum a todas elas estão as utilizações de estratégias de marketing por meio da comunicação e interação com o mercado, com o foco principal de conquistar e reter clientes. Por isso, a gestão comercial visa atuar de forma estratégica na empresa, indicando oportunidades a serem exploradas e garantindo o sucesso e o crescimento do negócio.

Neste contexto, o objetivo geral deste artigo é verificar se as MPEs do Sudoeste do Paraná aplicam ferramentas estratégicas de gestão comercial. Mais especificamente, pretende-se verificar como utilizam estratégias nas três principais etapas da administração de vendas: pré-venda, venda e pós-venda, além de verificar quais são as mais utilizadas.

A literatura científica tem apresentado um aumento no número de estudos relacionados às MPEs na última década, dado que essas empresas compõem a maioria dos empreendimentos nacionais, justificando, assim, essa grande expansão nas pesquisas. Contudo, o grande foco dos estudos tem se concentrado no tema empreendedorismo, sendo que ainda há lacuna na literatura no que concerne às pesquisas analisando a gestão comercial nesses empreendimentos.

Para melhor compreensão do artigo, o mesmo está estruturado em cinco seções, incluindo esta introdução. $\mathrm{Na}$ seção seguinte serão apresentados alguns conceitos e estratégias indicadas para se utilizar na gestão comercial das empresas. Na terceira, será descrita a metodologia empregada, seguida pela quarta seção, em que serão apresentados os resultados. E por fim, posterior aos resultados, serão apresentadas as considerações finais. 


\section{Referencial Teórico}

A gestão comercial está fundamentada na direção de estratégias de compras, no planejamento das ações de marketing e na administração de vendas (MENDES, 2017). Nesse sentido, todo o processo de decisão de compra do cliente passa por cinco fases, as quais as empresas devem conhecer detalhadamente uma a uma, visando aumentar a venda e a satisfação do cliente. Conforme Cônsoli, Castro e Neves (2007), a primeira fase consiste no reconhecimento da necessidade de compra, o qual está atrelado aos valores e necessidades pessoais do cliente. A segunda fase trata da busca de informações, que ocorre por meio de fontes internas (memória) e externas (mercado). A terceira considera a avaliação de alternativas, ou seja, quando o cliente escolhe dentre os produtos ou serviços ofertados aquele que mais atende aos seus critérios e o que mais valoriza. Essas três primeiras fases estão relacionadas à pré-venda.

A venda só ocorre na quarta fase, ou seja, na decisão de compra, em que o cliente de fato escolheu o produto ou serviço. Por fim, na quinta fase, ocorre o pós-venda, quando o cliente irá comparar as suas expectativas e o produto ou serviço, o qual pode gerar satisfação ou não. Nesta fase, o cliente utiliza os canais de comunicação para compartilhar aos demais interessados no produto a sua experiência (CÔNSOLI; CASTRO; NEVES, 2007).

A fim de uma melhor compreensão do referencial teórico, é oportuno apresentar a distinção entre cliente e consumidor. Considera-se consumidor todo indivíduo que toma a decisão de compra baseada no atendimento às suas necessidades pessoais. Quando essa experiência de compra é seguida pela fidelidade de compra e interesse pelo estabelecimento comercial, esse consumidor torna-se cliente (ASSIS, 2011). Desse modo, o presente trabalho adotou como padrão a definição de cliente, uma vez que o mesmo está inserido em todas as etapas de uma venda. Para a continuidade desta seção, optou-se por apresentar a mesma subdividida em três pontos principais: o pré-venda, venda e pós-venda.

\section{Pré-venda}

Há momentos no processo de venda que a empresa deve buscar novas oportunidades, novos clientes a qual é denominada de prospecção (CÔNSOLI; CASTRO; NEVES, 2007). Para que essa fase ocorra é necessário que a empresa considere informações a respeito das origens dos novos clientes. Ainda de acordo com os referidos autores, essas informações são possíveis de serem obtidas, pois, por exemplo, tratam-se das características demográficas, geográficas, comportamentais, indicações comerciais, rede de influência, dentre outras informações.

As características elencadas anteriormente possibilitarão às empresas criarem estratégias de acordo com o público-alvo do seu produto, ou seja, segmentar o mercado em que pretendem atuar, viabilizando a estratégia de nicho de mercado. A ênfase deve ocorrer no segmento em que os clientes possuem determinadas características e valor percebido sobre o produto ou serviço a ser ofertado. Desse modo, a empresa conseguirá responder de forma mais eficaz aos desejos dos clientes potenciais e, consequentemente, aumentar as vendas (KERIN et al. 2007; COBRA, 2014).

Conhecer as características dos clientes permite que as empresas os segmentem, agrupando-os assim de acordo com necessidades comuns e que respondem de forma similar às estratégias desenvolvidas (KERIN et al., 2007). Dessa maneira, conforme Churchill Júnior e Peter (2012), os clientes podem ser segmentados, mais comumente, por suas características geográficas, demográficas e psicográficas.

A segmentação que ocorre por meio das características demográficas está relacionada à idade, sexo, estado civil, gênero, etnia, renda, tamanho da família, ocupação e educação (KERIN et al., 2007; CHURCHILL JÚNIOR; PETER, 2012). Ainda para os autores citados, as características geográficas 
dos clientes podem ser de acordo com região onde moram, tamanho da cidade, clima, densidade urbana e rural. Por outro lado, conforme observavam Cônsoli, Castro e Neves (2007), características comportamentais ou psicográficas são úteis na segmentação dos clientes quando considerado o estilo de vida, personalidade e cultura.

Portanto, ressalta-se a importância de conhecer os clientes para que ocorra a escolha dos canais de comunicação adequados, e essa consiga atingir o público-alvo da empresa. Para Kotler e Armstrong (2015), esses canais podem ser pessoais ou não pessoais. O primeiro trata sobre a comunicação que corre diretamente entre duas ou mais pessoas. Por outro lado, os canais de comunicação não pessoais versam sobre mídias impressas, as de rádio ou televisão, expositiva (como placas e outdoors), a mídia on-line (que ocorre por meio das redes sociais) e web sites.

Para que a comunicação seja eficiente, faz-se necessário direcioná-la de acordo com as características dos clientes. Para tanto, a empresa pode utilizar como estratégia de pré-venda para atingir seu públicoalvo: amostra ou demonstração do produto ou serviço (que possibilitam maior obtenção de confiabilidade e demonstração da qualidade da mercadoria ofertada) e participação em feiras (a qual vislumbra resultados positivos, principalmente com negociações futuras), entre outras. Essas estratégias são consideradas fontes de informações para os clientes dos produtos ou serviços que a empresa disponibiliza (LAS CASAS, 2006a; CỐNSOLI; CASTRO; NEVES, 2007).

Muitas dessas informações podem ser obtidas por meio da divulgação de propaganda dos produtos e serviços, a qual tornou-se o meio mais comumente utilizado pelas empresas, pois é uma das ferramentas mais importantes da comunicação. Sua utilidade encontra-se no fato de que, durante um tempo determinado, possibilita informar, persuadir e lembrar o cliente sobre os produtos ou serviços que estão sendo ofertados, agregando valor para os mesmos (LAS CASAS, 2006b; CÔNSOLI; CASTRO; NEVES, 2007; CHURCHILL JÚNIOR; PETER, 2012; KOTLER; ARMSTRONG, 2015).

Sabe-se que grande parte das comunicações entre empresas e clientes ocorre através da propaganda. Observa-se que o objetivo principal da mesma é a geração de fluxo de clientes, vendas de produtos ou serviços, construção e fixação de imagem da empresa (LAS CASAS, 2006b). Ainda para o autor, a propaganda pode se dividir em dois tipos: a promocional e a institucional. A primeira se refere à venda direta, com enfoque na comercialização; o segundo tipo está relacionado à imagem da empresa e de seus produtos ou serviços, a qual serve como lembrete para quando o cliente precisar da empresa.

Em geral, dentre os meios utilizados para propaganda, os mais habituais são: jornais, televisão, maladireta, rádio, revistas, outdoor, internet, boca a boca, brindes, cartões de visita, placas nas ruas, patrocínio e telemarketing (CÔNSOLI; CASTRO; NEVES, 2007).

Portanto, após a identificação dos clientes potenciais para a empresa, que foram segmentados através de suas características e formulado um canal de comunicação específico, em que as informações foram repassadas por meio da propaganda, é necessário compreender quais fatores impactam na fase de venda, o que será tratado na seção a seguir.

\section{Venda}

Empresas de pequeno porte iniciam suas atividades quase exclusivamente com o objetivo apenas de vender os produtos e serviços que oferecem, sem definirem e programarem as ações de marketing e vendas. Não raro essas duas ações são enquadradas na mesma função, ou seja, nas MPEs não há um departamento específico para o marketing ou para venda (GOBE et al., 2007). Todavia, os referidos autores ressaltam que a implementação de ferramentas existentes no marketing pode agregar grande valor às vendas dessas micro e pequenas empresas.

Nesse sentindo, evidencia-se a importância de as empresas definirem quais são as estratégias para fidelização dos clientes. Uma dessas estratégias é quanto à formulação do preço. Conforme Kerin et al. 
(2007), preço é o dinheiro trocado pela propriedade ou pelo uso de um produto ou serviço. O preço deve ser definido levando em consideração os custos de produção, a concorrência, a demanda no mercado, além da diferenciação e qualidade. Segundo Churchill Júnior e Peter (2012), o preço baseado nos custos de produção é uma técnica em que as empresas determinam o custo para produzirem e comercializarem determinado produto, assegurando que o preço de venda seja mais alto que o custo de produção.

As empresas também podem definir seus preços por meio da concorrência, sendo que, neste caso, dependerá se o preço do produto ofertado praticado no mercado em questão está alto ou baixo. Porém, é necessário que as empresas estejam atentas aos baixos preços, pois estes podem levar ao prejuízo quando não cobrirem os custos do produto, acarretando problemas financeiros mais graves no longo prazo. Caso as empresas passem a disputar o cliente limitando-se apenas ao fator preço, adversidades poderão surgir, uma vez que utilizar uma estratégia de precificação em demasia pode ocasionar em guerra de preço, cenário no qual poucas empresas conseguem sobreviver, ficando no mercado apenas aquelas que conseguem produzir com economias de escala (CHURCHILL JÚNIOR; PETER, 2012).

Nesse sentido, a precificação por demanda também é outra estratégia que pode ser utilizada pelas empresas. Para Churchill Júnior e Peter (2012), essa estratégia pode ser dividida em duas, a saber: a demanda fraca e forte. A demanda fraca está relacionada à baixa procura por determinados produtos e serviços. Já com relação à demanda forte, a procura ocorre em grande escala. No último caso, as empresas devem reavaliar o preço praticado, verificar se o aumento da produção é viável ou, ainda, se é necessário aumentar o preço para reduzir a demanda (CHURCHILL JÚNIOR; PETER, 2012).

Sobre a estratégia de diferenciação, Porter (2004) atribui sua essência à característica voltada aos investimentos na imagem dos produtos ou serviços da empresa, nos canais de distribuição utilizados, na capacitação e assistência técnica que a empresa oferece, e que seus concorrentes não possuem. Por fim, há a estratégia de qualidade, relacionada à determinação do preço por desnatamento, ou seja, a qualidade e a imagem devem dar respaldo a seu preço elevado e que satisfaça as necessidades dos clientes. Para que tal estratégia se mantenha eficaz deve haver barreiras para a entrada de concorrentes no mercado e o oferecimento de produtos a preços menores (KERIN et al., 2007; CHURCHILL JÚNIOR; PETER, 2012; KOTLER; ARMSTRONG, 2015). Neste aspecto, conforme observa Gobe et al. (2007), a qualidade é definida como fator crítico para o sucesso das empresas.

Um incentivo de valor no curto prazo oferecido pelas empresas para aumentar e persuadir a compra são as promoções de vendas (KERIN et al., 2007; CHURCHILL JÚNIOR; PETER, 2012). Devido à sua característica intrínseca, muitas vezes a promoção se restringe apenas em vendas esporádicas e no curto prazo. Por isso, a empresa não deve depender apenas desta estratégia para vender, mas, sim, utilizá-la como suporte para fidelização dos clientes (KERIN et al., 2007).

Há diversos tipos de promoções que as empresas podem realizar, como, por exemplo, os cupons, ofertas, brindes, concursos, sorteios, amostras, programas de fidelidade, reembolsos, inserção de produtos, dentre outras opções (KERIN et al., 2007).

Logo, essas estratégias supracitadas devem ter seu respaldo na caracterização dos clientes a que a empresa atende. Portanto, as empresas necessitam estarem atentas às mudanças que ocorrem no ambiente no qual estão inseridas, ambiente esse constituído por participantes e forças externas, que afetam a capacidade de construir e manter bons relacionamentos com os clientes-alvos (KOTLER; ARMSTRONG, 2015). Ainda segundo os referidos autores, o cenário em que a empresa está inserida pode ser divido em microambiente, o qual está relacionado aos agentes próximos da empresa (fornecedores, concorrentes e a própria empresa) e o macroambiente, que relaciona as forças externas mais amplas, como as demográficas, econômicas, naturais, tecnológicas, políticas e culturais.

De acordo com Kotler e Armstrong (2015), as empresas não devem agir somente pela conduta do mercado, mas analisar as forças ambientais e desenvolver estratégias que ajudarão a evitar as ameaças e obter vantagens competitivas por meio das oportunidades oferecidas pelo seu ambiente, ou seja, devem criar estratégias para defini-lo. Então, para a empresa sobreviver, é necessário que a mesma monitore o 
seu ambiente constantemente e se antecipe aos acontecimentos (GOBE et al., 2007).

Entre os estudos científicos que abordam essa temática, a maioria se encontra no eixo do marketing. Nessa perspectiva, a pesquisa de Teixeira (2004) teve como objetivo analisar aspectos da gestão de marketing em empresas hoteleiras de pequeno porte localizadas no estado de Sergipe. Dentre as principais conclusões, a autora destaca que nas empresas pesquisadas a gestão de marketing é considerada pouco técnica, sendo "baseada no feeling dos seus proprietários, fato comum em empresas de pequeno porte” (TEIXEIRA, p. 23, 2004).

Com o objetivo de verificar os fatores que influenciam a na seleção dos canais de divulgação das empresas do setor de móveis planejados no município de Santa Maria, estado do Rio Grande do Sul, Vargas, Trindade e Horbe (2014) concluíram que as empresas tomam essas decisões sem a definição de critérios que possam embasar a escolha, o qual representa uma lacuna entre conhecimento e técnica.

Já Coelho et al. (2015) identificaram as estratégias da gestão de marketing em MPEs a partir da aprendizagem dos gerentes e proprietários de 40 empresas localizadas em Goiânia e região metropolitana. Os autores concluíram que os gerentes aprendem a administrar as empresas através das suas experiências e da dinâmica do mercado, e que os aspectos como o relacionamento, comunicação boca a boca e o diálogo com o cliente são praticados nas MPEs sem a consciência de serem ações de marketing sistematizadas.

Diante dos resultados encontrados nessas pesquisas, foi possível identificar que as decisões das MPEs sobre marketing se limitam basicamente às experiências proporcionadas pelo mercado ou na ação dos concorrentes.

\section{Pós-venda}

O pós-venda não pode ser considerado a última etapa do processo de venda, mas, sim, o início de novas vendas que as empresas poderão realizar, sendo algumas orientadas por meio dos atendimentos das solicitações dos clientes. Esta etapa ocorre após a compra efetuada ou o serviço realizado para o cliente. Trata-se de uma relação de longo prazo. Portanto, as empresas devem estar atentas a esse quesito para garantir a satisfação e fidelização dos seus clientes.

A ação do pós-venda deve ser realizada por meio de um conjunto de atividades, acompanhamento e manutenção de relacionamento com o cliente (CÔNSOLI; CASTRO; NEVES, 2007). Para tanto, existem diferentes condutas direcionadas aos clientes, as quais agregam valor e mantêm um relacionamento duradouro.

De acordo com Gobe et al. (2007), a pesquisa de satisfação é uma das principais estratégias que as empresas podem utilizar, pois possibilita verificar se o cliente utilizou o produto ou serviço, mensurando o grau de satisfação com o mesmo. Esse tipo de estratégia direciona as ações de vendas, aprimora a mercadoria e ajuda prever as oportunidades. Há também o serviço de atendimento ao consumidor (SAC), o qual, se bem trabalhado, pode antecipar as correções futuras provenientes do mal funcionamento de um equipamento ou insatisfação com um serviço realizado, apontando soluções aos problemas dos clientes. Essa ação permite maior proximidade com os clientes e fornece informações para que a empresa se diferencie das demais e assim fidelize os clientes.

As ações de pós-venda ainda podem estar relacionadas à instalação, assistência técnica, garantia ou cursos para manuseio adequado do produto comprado. A instalação diz respeito aos produtos que necessitam de mão de obra qualificada, sendo considerada uma extensão da venda e busca a satisfação do cliente. A assistência técnica ou garantia refere-se à tranquilidade e segurança no momento da compra, e funciona como um diferencial. Já os cursos para o uso e manuseio, tratam sobre treinamentos que as empresas oferecem para melhor utilizar o produto recém-adquirido, aproveitando, assim, todos os benefícios possíveis disponíveis para uso, elevando a satisfação do cliente (GOBE et al., 2007). 


\section{Método}

Visando atender aos objetivos propostos, o presente estudo adotou como procedimento metodológico as abordagens qualitativa e descritiva. De acordo com Rampazzo (2013), esse tipo de procedimento possibilita a construção de perfis ou cenários. A seguir, serão apresentados de forma mais detalhada os métodos para seleção da amostra relativa à população de estudo.

\section{População do Estudo}

A população selecionada como amostra para a realização dessa pesquisa restringiu-se às micro e pequenas empresas, além dos microempreendedores individuais, todos localizadas na mesorregião Sudoeste do Paraná.

Para tanto, optou-se por utilizar a técnica não probabilística por conveniência para a seleção da amostra. Conforme Mattar (2001), tal procedimento para a escolha dos elementos da população que irá compor a amostragem da pesquisa ocorre por estes estarem disponíveis no local e no momento em que a mesma estava sendo realizada, além de dispostas a colaborarem. Evidencia-se, ainda, que esse tipo de procedimento amostral tem por objetivo obter conhecimento sobre um fenômeno, indivíduos ou eventos, necessitando que o pesquisador, nesse caso qualitativamente, selecione os indivíduos que se adequem diretamente ao tema proposto, visando, assim, aumentar a compreensão sobre o fenômeno que se almeja analisar (ONWUEGBUZIE; LEECH, 2007).

A técnica de seleção amostral apresentada não é novidade nos trabalhos relativos à área de Administração. Perin et al. (2002) analisaram por uma década os procedimentos metodológicos de artigos publicados na área de marketing em um dos principais congressos nacionais de Administração e demonstraram que $81,7 \%$ dos trabalhos seguiam o método não probabilístico, sendo que destes, 28,95\% eram por conveniência. Oliveira et al. (2017), atualizando os números do estudo citado anteriormente para a última década, concluíram que $76 \%$ dos artigos apresentados em eventos científicos e nos principais periódicos de Administração no Brasil trabalharam com amostragem não probabilística, em que a seleção por conveniência apresentou significativa elevação, passando para 51,5\% de representatividade. Contudo, conforme recomenda Fávero et al. (2009), para aplicação desse tipo de técnica são necessários alguns cuidados, principalmente em relação à amostra, pois se esta não for homogênea, pode acontecer então de não representar a população, impedindo, deste modo, que tal técnica de amostragem seja aplicada. Com base nessa orientação, preocupou-se neste estudo para não se incorrer em tal falha. Ademais, essa técnica também foi escolhida por abranger o maior número de participação de respondentes, dadas as características de aplicação dos questionários, conforme será apresentado na seção seguinte.

Dessa forma, a Tabela 1 apresenta os municípios participantes e a respectiva quantidade de respondentes, representando a totalidade da amostra.

\begin{tabular}{c|c}
\hline Municípios & Total de respondentes \\
\hline Francisco Beltrão & 60 \\
\hline Realeza & 19 \\
\hline Planalto & 15 \\
\hline Mangueirinha & 13 \\
\hline São Jorge D’ Oeste & 5 \\
\hline Perola D’Oeste & 4 \\
\hline Pranchita & 2 \\
\hline Clevelândia & 1 \\
\hline Santa Izabel do Oeste & 1 \\
\hline Santo Antônio do Sudoeste & 1 \\
\hline São João & 1 \\
\hline Total & $\mathbf{1 2 2}$
\end{tabular}

Tabela 1 - Amostra dos municípios da mesorregião Sudoeste do Paraná com o respectivo número de participantes da pesquisa

Fonte: Dados da pesquisa. 
Para a efetivação da pesquisa, elaborou-se um questionário, sendo que sua estruturação e demais informações serão apresentados no tópico seguinte.

\section{Coleta dos dados}

A coleta de dados ocorreu por meio de questionários aplicados presencialmente e online aos empresários que estavam participando do curso ofertado pelo Programa Bom Negócio Paraná ${ }^{\text {e }}$ estavam fazendo o módulo de gestão comercial e outros que já haviam participado do projeto. No total, o respondente deparava-se com 25 perguntas fechadas de múltipla escolha. Como instrumento de coleta de dados online, utilizou-se da plataforma Google Forms. Para tanto, enviou-se o questionário por e-mail para uma seleção de empresários que já haviam concluído o curso. O período de aplicação dos questionários ocorreu entre os meses de maio a agosto de 2018.

O questionário foi dividido em duas partes. A primeira referiu-se às características dos empreendimentos, enquanto a segunda buscou analisar a gestão comercial praticada pelas empresas. Para responder a primeira parte, elaboraram-se quatro questões, todas de múltipla escolha. A primeira dizia a respeito ao setor de atuação, sendo possível marcar mais de uma opção, as quais eram comércio, indústria e serviço. A segunda e terceira questões versaram sobre a localização do empreendimento, ou seja, onde estavam localizados e quais foram os motivos que levaram à escolha desse local. A quarta questão perguntou sobre o tipo de produtos e serviços ofertados, como exemplo, produtos alimentícios, artesanais, serviços de beleza, mecânica, vestuário, dentre outros.

A segunda parte do questionário foi estruturada para verificar as estratégias utilizadas pelas empresas na gestão comercial. As primeiras quatro questões buscaram aferir o perfil demográfico, geográfico e psicográfico dos clientes, as quais estão diretamente relacionadas à segmentação do público-alvo. Observa-se que na questão sobre o perfil psicográfico o entrevistado poderia assinalar somente uma alternativa, sendo que as demais poderiam admitir mais de uma opção.

As duas questões seguintes trataram sobre as estratégias de pré-venda utilizadas pelas empresas. A primeira perguntou sobre quais tipos de pré-venda a empresa prioriza, como por exemplo: amostras grátis, demonstração do produto e propaganda. A segunda questão abordou sobre os meios preferenciais de realizar propaganda, oferecendo como alternativas de respostas as opções de anúncio em rádio, televisão, jornal, propaganda boca a boca, panfletos, redes sociais, dentre outras. Nessas duas questões havia a possibilidade de os respondentes marcarem mais de uma alternativa em suas respostas. Para a realização das perguntas citadas anteriormente e suas alternativas, buscou-se na literatura embasamento teórico para tal, e os principais autores pesquisados foram Kerin et al. (2007), Cônsoli, Castro e Neves (2007), Churchill Júnior e Peter (2012), e Kotler e Armstrong (2015).

Para responder às indagações sobre a venda foram realizadas sete questões, as quais foram elaboradas de acordo com Porter (2004) e Churchill Júnior e Peter (2012). A primeira questão desse tópico tratou sobre a formação do preço, listando dentre as alternativas custo de produção, concorrência, demanda do mercado, diferenciação e qualidade. Nessa questão os respondentes poderiam escolher mais de uma opção dentre as elencadas. Na seguinte, abordou-se sobre o fator sazonalidade da demanda e, para tanto, questionou-se se como percebiam essa ocorrência na empresa. Para os que respondiam que havia sazonalidade, realizava-se outra pergunta, a qual indicava sobre quais eram as estratégias para diminuir tal evento, sendo que, dentre as opções, os respondentes poderiam optar por alternativas como variação de produtos, promoções, fidelização, entre outras.

A questão subsequente tratou sobre promoções. Para tanto, procurou-se averiguar se a mesma era utilizada e quando era aplicada tal estratégia, como, por exemplo, datas comemorativas, diminuição de vendas ou estoque sem giro. Aos que responderam que realizavam promoções, questionou-se como as realizavam, cujas opções de respostas foram: redução de preço, acréscimo de produto, combos, prazo 
de pagamentos, etc. Nessas duas questões os respondentes poderiam optar por mais de uma alternativa. Ambas as questões foram formuladas e teoricamente embasadas nos trabalhos de Kerin et al. (2007) e Churchill Júnior e Peter (2012).

Com relação às mudanças que ocorrem no mercado tanto no ambiente externo como interno, e com base em Kotler e Armstrong (2015), foram realizadas duas questões. A primeira averiguou como a empresa a detecta, sendo as opções elencadas: através das ações dos concorrentes, opiniões dos clientes, pesquisa de mercado, consultorias, palestras, entre outras. Nesta pergunta poderia escolher mais de uma opção. A segunda questão inquiriu como as empresas lidam com essas mudanças, tendo como alternativas de respostas: adaptação no mercado, cooperações com fornecedores, consultorias, imagem da empresa, dentre outras, em que era possível escolher somente uma opção.

Com relação aos concorrentes foram realizadas duas questões. A primeira verificou como os respondentes se diferenciam da concorrência, e as opções foram: bom atendimento, inovação, preço, fidelização e tempo no mercado. Já a questão seguinte perguntou sobre a localização dos concorrentes, isto é, se estão na mesma rua, no bairro, na cidade, na região, no estado, no país ou mesmo na internet. Nessas duas questões os respondentes poderiam escolher mais de uma opção de respostas. Ambas as questões explicadas acimas foram realizadas de acordo com Kotler e Armstrong (2015) e Gobe et al. (2007).

A última questão sobre as vendas perguntou como os atributos localização, atendimento, preço, estacionamento, qualidade e instalações ofereciam vantagem competitiva para a empresa. Nesta questão os respondentes tinham que dar uma nota considerando uma escala de zero a dez para cada item, em que zero significava pouco importante e dez muito importante.

Com relação ao pós-venda, realizou-se uma questão avaliando se as empresas adotavam ou não a utilização dessa estratégia, sendo que aquelas que não a utilizavam não responderiam as questões seguintes. Também se questionou sobre a importância dessa estratégia na percepção dos empresários, em que foi utilizada novamente a escala de zero a dez, conforme descrito anteriormente. Em seguida, conforme sugerem Gobe et al. (2007), perguntou-se quais ações de pós-venda são aplicadas, elencando como alternativas a satisfação do cliente, garantia, suporte técnico e divulgação de novos produtos. Nessa questão os respondentes tinham a opção de assinalar mais de uma alternativa. A próxima questão tratou sobre como a empresa se posiciona após a realização das ações de pós-venda, oferecendo como opções de alternativa: atende todas as sugestões dos clientes, atende parcialmente ou não atende. E, por fim, a última questão referiu-se sobre o tempo que a empresa leva para realizar o pós-venda com o cliente. Essas duas últimas questões o respondente só poderia assinalar uma alternativa.

Com o intuito de verificar a adequabilidade do questionário foi realizado um pré-teste com três empresários, procurando-se respeitar a representatividade da heterogeneidade da amostra. O pré-teste do questionário teve por objetivo verificar possíveis falhas, incompreensões, complexidade, ambiguidade ou linguagem inacessível, que podem trazer riscos à pesquisa (RAMPAZZO, 2013). Como resultado, algumas questões precisaram ser reescritas para uma melhor compreensão do entrevistado. Após as conferências da adequabilidade do questionário, iniciou-se o processo de coleta dos dados e posteriormente a sua análise.

\section{Análise e discussão dos resultados}

Essa seção será subdivida de acordo com a estrutura do questionário. Assim, a primeira apresentará as características dos empreendimentos. Na sequência, serão analisados e discutidos os resultados obtidos sobre o pré-venda, a venda e o pós-venda. 


\section{Características das empresas}

Conforme explanado anteriormente, primeiramente foi verificada a caracterização dos empreendimentos da amostra. Sobre o setor de atuação, verificou-se que 44,26\% das empresas pesquisadas atuam no setor de comércio, seguido de serviços $(38,52 \%)$ e indústria $(5,74 \%)$. Dentre as empresas respondentes, $5,74 \%$ atuam em conjunto no comércio e indústria, 4,10\% no comércio e serviço, 4,10\% atuam na indústria e serviço, e somente uma atua em todos os três setores, que representou $0,82 \%$ da amostra. Tal amostra corrobora com os dados nacionais, uma vez que pesquisas indicam que as atuações nos setores de comércio e serviços têm se mostrado mais significantes entre todos os setores das micro e pequenas empresas no Brasil (SANTOS, KREIN, CALIXTRE, 2012; CNDL; SPCBRASIL, 2015; DATASEBRAE, 2017).

Com relação aos produtos e serviços ofertados por esses empreendimentos, os produtos artesanais apresentaram maior peso na amostra, 20,30\% ao todo. Essa e demais informações, como os principais itens de comercialização e produção, estão apresentadas na Tabela 2, a seguir.

Com relação à localização, mais da metade dos respondentes afirmaram que seus empreendimentos se encontram próximos ao centro de suas cidades (44,26\%), sendo que, destes, 55,56\% indicaram que a escolha do local foi motivada por ser anexo à residência. Dados do Datasebrae (2017) demostraram que em âmbito nacional, os empreendimentos anexos às residências ocupam o segundo lugar, sendo o primeiro em estabelecimentos comercial/industrial. O Paraná está entre os quatro estados que possuem mais empresas nesta modalidade, juntamente com Rio Grande do Sul, São Paulo e Amazonas.

\begin{tabular}{c|c|c}
\hline Setor de atuação & Itens comercializados & $\begin{array}{c}\text { Respostas por } \\
\text { setor }(\mathbf{e m} \text { \%) }\end{array}$ \\
\hline \multirow{2}{*}{ Comércio } & Vestuário & 22,22 \\
& Alimentício & 18,52 \\
& Artesanais & 7,26 \\
& Produtos de limpeza & 1,41 \\
\hline \multirow{2}{*}{ Serviço } & Beleza & 8,51 \\
& Eletricista & 6,38 \\
\hline \multirow{2}{*}{ Indústria } & Artesanais & 6,38 \\
\hline \multirow{2}{*}{ Comércio e Indústria } & Mecânica & 28,57 \\
\hline \multirow{2}{*}{ Comércio e Serviço } & Cutelaria & 28,57 \\
\hline Indústria e Serviço & Móveis & 42,85 \\
\hline Serviço, Comércio e Indústria & Artesanais & 28,57 \\
\hline
\end{tabular}

Tabela 2 - Setor de atuação das MPEs da mesorregião Sudoeste do Paraná participantes da pesquisa e principais itens comercializados - 2018

Fonte: Dados da pesquisa.

Em relação às empresas que se localizam na área central (31,14\%), segunda maior área de concentração dos empreendimentos pesquisados, a justificativa mais encontrada foi devido ao grande fluxo de pessoas (47,37\%). Já aquelas que estão localizadas em regiões periféricas (15,58\%), optaram por esse local devido a estar próxima ou instalada na própria residência $(68,42 \%)$. Com relação às empresas que se localizam no interior (zona rural), 9,02\% optaram por esse local também por ser adjacente à residência $(45,45 \%)$.

Essa quantidade considerável de empresas que atuam anexas à residência pode ter sido fomentada pela Lei Complementar $\mathrm{n}^{\circ}$ 154, de 18 abril de 2016, a qual foi promulgada com o objetivo de viabilizar a 
regularização dos MEIs junto às residências, desde que o exercício da atividade não seja impróprio para a sua atuação (BRASIL, 2016).

A seguir, serão apresentados os resultados encontrados sobre a pré-venda, venda e pós-venda.

\section{Pré-venda}

Essa etapa da venda consiste em verificar quais são as estratégias adotas pelos empreendimentos pesquisados com relação à atração e retenção dos clientes. Para tanto, a Tabela 3, a seguir, demostra as principais estratégias utilizadas.

As quatro primeiras questões trataram sobre o perfil dos clientes e a definição do público-alvo. Conforme Kotler e Keller (2005), a definição do público-alvo, denominada de segmentação, deve ser realizada para que as empresas se adaptem de forma lucrativa e reconheçam as diferenças de seus clientes.

Com relação à segmentação demográfica, os resultados demostraram que as empresas atuam em sua maior parte atendendo ao sexo feminino, destacando-se os produtos artesanais (15,91\%), os serviços de beleza $(15,91 \%)$ e o vestuário (11,36\%). Além dos principais resultados demostrado na Tabela 3 , destaca-se que apenas três empresas atendem ao sexo masculino e pessoa jurídica, em conjunto, as quais representam 2,50\% dos respondentes, essas empresas atuam no setor peças de restauração e mecânica. E apenas uma empresa atente ao sexo feminino e pessoa jurídica $(0,89 \%)$ a qual fornece produtos de limpeza. Em relação à idade, os respondentes demostraram que buscam atender diferentes tipos de clientes.

\begin{tabular}{|c|c|c|c|c|c|}
\hline Perguntas & \multicolumn{5}{|c|}{ Respostas } \\
\hline $\begin{array}{l}\text { Perfil dos clientes } \\
\text { por gênero }\end{array}$ & $\begin{array}{l}\text { Feminino } \\
(36,88 \%)\end{array}$ & $\begin{array}{c}\text { Feminino/ } \\
\text { Masculino } \\
(21,31 \%)\end{array}$ & $\begin{array}{l}\text { Masculino } \\
(17,21 \%)\end{array}$ & $\begin{array}{l}\text { Pessoa Jurídica } \\
(11,46 \%)\end{array}$ & $\begin{array}{l}\text { Todas as opções } \\
(9,82 \%)\end{array}$ \\
\hline $\begin{array}{c}\text { Caracterização } \\
\text { dos clientes por } \\
\text { idade }\end{array}$ & $\begin{array}{l}\text { Adultos } \\
(49,18 \%)\end{array}$ & $\begin{array}{c}\text { Adultos/ } \\
\text { Pessoas Jurídicas } \\
(9,02 \%)\end{array}$ & $\begin{array}{l}\text { Adultos/ } \\
\text { Idosos } \\
(6,56 \%) \\
\end{array}$ & $\begin{array}{c}\text { Adolescentes/ } \\
\text { Adultos } \\
(5,74 \%) \\
\end{array}$ & $\begin{array}{l}\text { Pessoas Jurídicas } \\
\qquad(4,92 \%)\end{array}$ \\
\hline $\begin{array}{l}\text { Renda domiciliar } \\
\text { dos clientes }\end{array}$ & $\begin{array}{c}\text { Não faz } \\
\text { classificação } \\
\text { por renda } \\
(50 \%) \\
\end{array}$ & $\begin{array}{c}\text { Entre } 1 \text { e } 2 \\
\text { salários mínimos } \\
(22,13 \%)\end{array}$ & $\begin{array}{l}\text { Entre } 2,1 \text { e } 4 \text { salários } \\
\text { mínimos }(14,75 \%)\end{array}$ & $\begin{array}{l}\text { Não respondeu } \\
(8,20 \%)\end{array}$ & $\begin{array}{c}\text { Acima de } 4 \text { salário } \\
\text { mínimos } \\
(4,92 \%)\end{array}$ \\
\hline $\begin{array}{l}\text { Definição do } \\
\text { público-alvo }\end{array}$ & $\begin{array}{c}\text { Não realiza } \\
\text { classificação } \\
(67,21 \%)\end{array}$ & $\begin{array}{l}\text { Estilo de vida } \\
\qquad(9,84 \%)\end{array}$ & $\begin{array}{c}\text { Comportamento } \\
(6,56 \%)\end{array}$ & $\begin{array}{l}\text { Personalidade } \\
\qquad(5,74 \%)\end{array}$ & $\begin{array}{l}\text { Cultura } \\
(3,28 \%)\end{array}$ \\
\hline $\begin{array}{l}\text { Ações de pré- } \\
\text { venda mais } \\
\text { utilizadas }\end{array}$ & $\begin{array}{l}\text { Mesclam } \\
\text { estratégias } \\
(42,62 \%)\end{array}$ & $\begin{array}{l}\text { Propaganda } \\
(26,23 \%)\end{array}$ & $\begin{array}{c}\text { Nenhuma ação de } \\
\text { pré-venda } \\
(15,57 \%)\end{array}$ & $\begin{array}{c}\text { Participação em } \\
\text { feiras } \\
(6,56 \%)\end{array}$ & $\begin{array}{c}\text { Demonstração do } \\
\text { produto/ } \\
\text { serviço } \\
(4,92 \%)\end{array}$ \\
\hline $\begin{array}{c}\text { Meios } \\
\text { preferenciais de } \\
\text { propaganda }\end{array}$ & $\begin{array}{c}\text { Boca a Boca/ } \\
\text { Rede Social } \\
(13,96 \%)\end{array}$ & $\begin{array}{c}\text { Boca a Boca/ } \\
\text { Rede Social/ } \\
\text { Cartão de Visita } \\
(12,29 \%)\end{array}$ & $\begin{array}{c}\text { Boca a Boca } \\
\quad(8,19 \%)\end{array}$ & $\begin{array}{l}\text { Rede Social } \\
(7,38 \%)\end{array}$ & $\begin{array}{c}\text { Boca a Boca/ } \\
\text { Cartão de Visitas/ } \\
\text { Panfletos/ Rede } \\
\text { Social } \\
(3,28 \%)\end{array}$ \\
\hline
\end{tabular}

Tabela 3 - Práticas de pré-venda realizadas pelas MPEs da mesorregião Sudoeste do Paraná participantes da pesquisa - 2018

Fonte: Dados da Pesquisa.

Apesar da maioria das empresas atenderem pessoas físicas, representando $77,87 \%$ do público atendido pela amostra, no contexto geral, corroborando com os dados nacionais obtidos pelo Datasebrae (2017), em que o setor privado é o principal mercado das micro e pequenas empresas. Contudo, 22,12\% também têm como público-alvo empresas jurídicas. Cabe destacar que a comercialização de empresas 
para empresa (B2B) são frequentes nas MPEs, em que, no Brasil, 55\% sempre buscam esse tipo de comercialização dentre as empresas jurídicas, e 33\% das empresas já venderam produtos ou serviços para órgãos públicos, o qual é considerado um diferencial no faturamento dessas empresas (DATASEBRAE, 2017).

As duas últimas questões sobre a segmentação de mercado foram sobre a classificação dos clientes com relação à renda e o perfil psicográfico. Dentre as empresas que realizam a classificação por renda, $7,84 \%$ comercializam ou produzem alimentos, e outras $13,72 \%$ vendem produtos artesanais. Contudo, nos empreendimentos que não realizam a classificação por renda, 14\% atuam no ramo alimentício, 12\% no setor de beleza e vestuário, $6 \%$ comercializam produtos artesanais.

Com relação à definição de público-alvo, dentre os respondentes que não realizam essa classificação, a maioria atua no ramo artesanal e de beleza. Apenas uma empresa realiza todas as definições de públicoalvo conforme descrito na Tabela 3, sendo que esta atua no setor artesanal. Outros 4,92\% não sabem ou não responderam essa questão, sendo estas atuantes nos setores de entretenimento, alimentício, artesanal, beleza e mecânico.

Tais resultados demostram que grande parte das empresas pesquisadas não conhece seus clientes ou não busca conhecê-los, deixando, por exemplo, de traçar o perfil psicográfico de seu público-alvo. Conforme Kotler e Keller (2005), a segmentação é útil para as empresas, pois divide os clientes em grupos mais específicos, já que, por exemplo, dentro da segmentação geográfica pode haver diferentes segmentações psicográficas. Com isso, segundo Kerin et al. (2007), as empresas deixam de formular estratégias para conquistar os grupos específicos aos quais atendem. Sendo que essa dificuldade de encontrar e reter clientes é a principal dificuldade das MPEs, no dia a dia, e uma das principais causas do encerramento das atividades dessas empresas (DATASEBRAE, 2017).

Apesar dos resultados apresentados acima, destaca-se o fato de que as empresas buscam concentrar seus esforços apenas em vender seus produtos e, para tanto, procuram mesclar estratégias para conseguir atrair clientes. Entre as principais estratégias que os respondentes afirmam utilizar no prévenda, $19,23 \%$ citaram propaganda e participação em feiras, $17,31 \%$ responderam panfleto e propaganda, e 13,46\% lembraram demonstração do produto e propaganda.

A estratégia de pré-venda mais empregada pelas MPEs do Sudoeste do Paraná é a propaganda $(26,23 \%)$. Ficou perceptível que as empresas utilizam diferentes estratégias, pois foram encontrados 56 diferentes tipos, esse número expressivo ocorreu porque as empresas poderiam escolher mais de uma opção entre as apresentadas no questionário de coleta de dados. Porém, apenas 2,46\% não realizam estratégias de pré-venda, empresas que atuam no ramo alimentício, produções artísticas e artesanais.

Conforme recomenda Cônsoli, Castro e Neves (2007), uma comunicação eficaz entre empresas e clientes propicia bons resultados, contudo é necessário que se conheça o perfil dos clientes para então direcionar os melhores canais de comunicação. Todavia, os respondentes não realizam esse tipo de pesquisa para conhecerem o perfil dos seus clientes, conforme evidenciado na Tabela 3. O que justifica os diversos canais de comunicação utilizados para tentar conquistar o maior número de clientes possíveis, o que, por fim, encarece o custo de marketing. De acordo com Vargas, Trindade e Horbe (2014), realmente há essa dificuldade em encontrar um canal claro de comunicação com os clientes por parte da empresa, o qual é influenciado pela lacuna entre conhecimento e técnica.

\section{Venda}

Esta sessão tratará sobre as estratégias de venda que as empresas utilizam, para tanto as perguntas foram direcionadas para as estratégias de vendas e comercialização dos produtos e serviços. Nesse sentido, a Tabela 4 demostra de forma geral os principais resultados.

A primeira questão de venda tratou sobre a formação de preço. Conforme os resultados da Tabela 4, a 
estratégia mais utilizada pelas empresas foi qualidade. De acordo com Gobe et al. (2007), a qualidade que as empresas repassam aos seus clientes é definida como um fator de sucesso, o que justifica os seus preços e satisfaz a necessidade dos clientes. Obtiveram-se também resultados expressivos sobre os que buscam mesclar essas estratégias, o que representa 50,82\% dos respondentes, e as estratégias mais utilizadas em conjunto são custo de produção e qualidade $(12,30 \%)$ e diferenciação e qualidade $(6,56 \%)$.

Quando indagados sobre a percepção de mudanças na demanda do seu produto ou serviço em determinadas épocas do ano, $81,15 \%$ responderam que percebem essas mudanças, $13,11 \%$ que não a percebem e $5,74 \%$ não souberam ou não responderam. Dentre as empresas que percebem essas sazonalidades, as alternativas mais utilizadas para diminuí-las, além das apresentadas na Tabela 4, foram citadas promoção e fidelização de clientes $(9,84 \%)$, variedade de produtos e fidelização $(7,38 \%)$ e com a mesma representatividade da estratégia anteriormente citada, variedade atrelada a promoções.

\begin{tabular}{|c|c|c|c|c|c|}
\hline Perguntas & \multicolumn{5}{|c|}{ Respostas } \\
\hline $\begin{array}{l}\text { Considerações para a } \\
\text { formação de preço }\end{array}$ & $\begin{array}{l}\text { Qualidade } \\
(22,95 \%)\end{array}$ & $\begin{array}{l}\text { Custo de } \\
\text { produção/ } \\
\text { Compra } \\
(12,30 \%) \\
\end{array}$ & $\begin{array}{c}\text { Estudo da } \\
\text { concorrência } \\
\quad(5,74 \%)\end{array}$ & $\begin{array}{l}\text { Diferenciação } \\
\quad(3,28 \%)\end{array}$ & $\begin{array}{l}\text { Demanda } \\
(3,28 \%)\end{array}$ \\
\hline $\begin{array}{c}\text { Estratégias utilizadas } \\
\text { para superar } \\
\text { problemas de } \\
\text { sazonalidade }\end{array}$ & $\begin{array}{l}\text { Mesclam } \\
\text { estratégias } \\
(34,43 \%)\end{array}$ & $\begin{array}{l}\text { Fidelização de } \\
\text { clientes } \\
(15,57 \%)\end{array}$ & $\begin{array}{l}\text { Variedade de } \\
\text { produtos } \\
(13,93 \%)\end{array}$ & $\begin{array}{l}\text { Não utiliza } \\
\text { estratégias } \\
(9,84 \%)\end{array}$ & $\begin{array}{c}\text { Promoções } \\
(8,20 \%)\end{array}$ \\
\hline $\begin{array}{l}\text { Cenário do mercado } \\
\text { na utilização de } \\
\text { promoções }\end{array}$ & $\begin{array}{c}\text { Não realiza } \\
\text { promoções } \\
(34,43 \%)\end{array}$ & $\begin{array}{c}\text { Mesclam estratégias } \\
(26,4 \%)\end{array}$ & $\begin{array}{c}\text { Diminuição das } \\
\text { vendas } \\
(13,93 \%)\end{array}$ & $\begin{array}{l}\text { Estoque sem giro } \\
\qquad(9,02 \%)\end{array}$ & $\begin{array}{c}\text { Datas } \\
\text { comemorativas } \\
(9,02 \%)\end{array}$ \\
\hline $\begin{array}{l}\text { Estratégias } \\
\text { promocionais } \\
\text { utilizadas }\end{array}$ & $\begin{array}{l}\text { Mesclam } \\
\text { promoções } \\
(38,82 \%) \\
\end{array}$ & \begin{tabular}{|c}
$\begin{array}{c}\text { Redução de preço/ } \\
\text { descontos } \\
(32,94 \%)\end{array}$ \\
\end{tabular} & $\begin{array}{l}\text { Combos de } \\
\text { produtos } \\
(5,74 \%)\end{array}$ & $\begin{array}{l}\text { Parcelas sem juros } \\
\qquad(3,53 \%)\end{array}$ & $\begin{array}{l}\text { Maior prazo de } \\
\text { pagamento } \\
(3,53 \%)\end{array}$ \\
\hline $\begin{array}{c}\text { Meios de percepção } \\
\text { das mudanças de } \\
\text { mercado }\end{array}$ & $\begin{array}{l}\text { Mesclam } \\
\text { estratégias } \\
(42,62 \%)\end{array}$ & $\begin{array}{l}\text { Opinião dos } \\
\text { clientes } \\
(28,69 \%)\end{array}$ & $\begin{array}{l}\text { Pesquisa de } \\
\text { mercado } \\
(8,20 \%)\end{array}$ & $\begin{array}{c}\text { Informações através } \\
\text { da TV } \\
\text { / rádio/internet } \\
(4,92 \%) \\
\end{array}$ & $\begin{array}{c}\text { Ações dos } \\
\text { concorrentes } \\
(4,92 \%)\end{array}$ \\
\hline $\begin{array}{l}\text { Ações ao perceber a } \\
\text { mudança de mercado }\end{array}$ & $\begin{array}{c}\text { Pensa na } \\
\text { imagem da } \\
\text { empresa } \\
\text { antes de } \\
\text { adaptar-se } \\
(31,96 \%)\end{array}$ & $\begin{array}{l}\text { Rápida adaptação } \\
\qquad(28,69 \%)\end{array}$ & $\begin{array}{l}\text { Busca alianças } \\
\text { com } \\
\text { fornecedores } \\
(22,95 \%)\end{array}$ & $\begin{array}{c}\text { Não vê necessidade } \\
\text { de mudança } \\
(10,66 \%)\end{array}$ & $\begin{array}{c}\text { Uso de consultoria } \\
\text { para melhor se } \\
\text { adaptar } \\
(5,74 \%)\end{array}$ \\
\hline $\begin{array}{c}\text { Atributos de } \\
\text { diferenciação frentes } \\
\text { aos concorrentes } \\
\end{array}$ & $\begin{array}{c}\text { Mesclam } \\
\text { estratégias } \\
(82,79 \%) \\
\end{array}$ & $\begin{array}{l}\text { Bom atendimento } \\
\qquad(5,74 \%)\end{array}$ & $\begin{array}{l}\text { Qualidade } \\
(5,74 \%)\end{array}$ & $\begin{array}{c}\text { Inovação } \\
(2,46 \%)\end{array}$ & $\begin{array}{l}\text { Preço } \\
(0,82 \%)\end{array}$ \\
\hline $\begin{array}{l}\text { Percepção da } \\
\text { localização dos } \\
\text { principais } \\
\text { concorrentes }\end{array}$ & $\begin{array}{c}\text { No município } \\
(41,80 \%)\end{array}$ & $\begin{array}{c}\text { Em diferentes } \\
\text { localidades } \\
(34,43 \%)\end{array}$ & $\begin{array}{l}\text { Na região } \\
(9,02 \%)\end{array}$ & $\begin{array}{l}\text { Na rua } \\
(4,09 \%)\end{array}$ & $\begin{array}{l}\text { Na internet } \\
(4,09 \%)\end{array}$ \\
\hline
\end{tabular}

Tabela 4 - Percepção das MPEs do Sudoeste do Paraná participantes da pesquisa sobre as ações de vendas e cenário de mercado - 2018

Fonte: Dados da pesquisa.

Com o intuito de compreender melhor as respostas da questão sobre sazonalidade e demanda, verificou-se quais eram as principais promoções realizadas pelas empresas pesquisadas. Identificou-se que $34,43 \%$ da amostra não realiza promoções de venda, sendo que dessas empresas, $50 \%$ atuam no setor de serviços e 33,33\% no comércio. Dentre as que utilizam mais de uma estratégia de promoção, $34,38 \%$ as utilizam basicamente em datas comemorativas e quando as vendas diminuem, e outras $28,13 \%$ mesclam as estratégias em datas comemorativas, diminuição de vendas e estoque sem giro.

Nessa perspectiva, indagou-se aos respondentes que realizam promoção de venda quais eram utilizadas. 
Houve bastante variedade de respostas, além daquelas apresentadas na Tabela 4, sendo as mais utilizadas, em conjunto: redução de preço/descontos, maior prazo para pagamento e parcelamento sem juros (18,18\%); redução de preço/descontos e combos $(18,18 \%)$; e redução de preço/descontos e promoção conforme evento no município/região (12,12\%).

As questões sobre venda também avaliaram as mudanças que ocorrem no mercado. Dessa forma, as duas questões seguintes adentrarão esse tema. Conforme a Tabela 4, quase metade dos respondentes $(42,62 \%)$ utilizam diversas formas de detectar as mudanças no mercado em que estão inseridos. Dentre as empresas que utilizam mais de uma estratégia, 15,38\% analisam as opiniões dos clientes e fazem pesquisa de mercado, 9,62\% verificam as ações dos concorrentes e a opinião dos clientes, outros 9,62\% também levam em consideração as opiniões dos clientes, buscam informações na televisão, rádio e/ou internet. E outros 4,10\% não identificam mudanças no mercado que estão inseridos.

Em relação aos concorrentes, identificou-se que muitas empresas utilizam mais de uma estratégia para se diferenciarem da concorrência, conforme demostrado na Tabela 4. Ao todo, 46 diferentes estratégias para se diferenciar da concorrência foram identificadas nas respostas, dentre as opções apresentadas no questionário. Em geral, foi possível perceber três grupos de respostas mais comuns que os empresários relataram dar destaque, quais são: a inovação e qualidade $(6,93 \%)$, o bom atendimento, qualidade e fidelização dos clientes (5,94\%), bom atendimento, preço e qualidade (5,94\%). Corroborando o resultado apresentado, Coelho et al. (2015), analisando 40 micro e pequenas empresas em Goiânia, também encontraram resultados atrelados à qualidade no atendimento ao cliente como a principal estratégia identificada para a diferenciação destas com os concorrentes. Apenas uma empresa não procura se diferenciar da concorrência, a qual atua no ramo de confecções e fornece seus produtos somente para pessoa jurídica.

Após serem questionados sobre as vendas e o mercado, as demais perguntas foram direcionadas para o quão importante são considerados os atributos instalações, estacionamento, preço, qualidade, atendimento e localização para a obtenção de vantagem competitiva. Para essas respostas, os empresários deveriam atribuir notas em uma escala de 0 a 10 , sendo zero para nada importante e dez para muito importante. Os resultados estão apresentados na Tabela 5 a seguir.

\begin{tabular}{|c|c|c|c|c|c|c|c|c|c|c|c|}
\hline \multirow{2}{*}{ Atributos } & \multicolumn{11}{|c|}{ Notas conferidas (em \%) } \\
\hline & $\mathbf{0}$ & 1 & 2 & 3 & 4 & 5 & 6 & 7 & 8 & 9 & 10 \\
\hline Instalações & 7,38 & 1,64 & 1,64 & 1,64 & 1,64 & 7,38 & 4,10 & 7,38 & 20,49 & 11,48 & 36,89 \\
\hline Estacionamento & 23,77 & 1,64 & 5,74 & 5,74 & 3,28 & 11,48 & 4,92 & 6,56 & 10,66 & 8,20 & 18,03 \\
\hline Preço & 0 & 0 & 0 & 0 & 0,82 & 12,30 & 4,10 & 9,02 & 26,23 & 13,11 & 34,43 \\
\hline Qualidade & 0,82 & 0 & 0 & 0 & 0 & 16,40 & 0 & 1,64 & 6,56 & 19,67 & 69,67 \\
\hline Atendimento & 0,82 & 0 & 0 & 0,82 & 0 & 0 & 0 & 4,10 & 13,11 & 15,57 & 65,57 \\
\hline Localização & 5,74 & 1,64 & 1,64 & 4,10 & 2,46 & 15,57 & 4,92 & 7,38 & 18,03 & 10,66 & 2,787 \\
\hline
\end{tabular}

Tabela 5 - Percepção das MPEs do Sudoeste do Paraná participantes da pesquisa sobre determinados atributos da empresa - 2018

Fonte: Dados da pesquisa.

Dentre os atributos pesquisados, os mais relevantes para as empresas foram: qualidade e atendimento, corroborando com a questão sobre diferenciação da concorrência. A alta importância da qualidade também pode estar atrelada ao preço dos produtos e serviços dessas empresas, já que os mesmos relataram que o seu preço é definido pela qualidade. Contudo, a baixa importância em relação ao estacionamento e a localização podem estar ligadas às características dos municípios nas quais as empresas atuam, os quais são pequenos, onde há vagas para os veículos em via pública e ao endereço que estão situadas (44,26\% anexo as residências). 


\section{Pós-vendas}

Este tópico abordará somente o pós-venda das empresas. Para tanto, verificou-se como as micro e pequenas empresas e os microempreendedores individuais implantam tal ação e as demais estratégias sugeridas pela teoria no que concerne este tema. Entre as empresas entrevistadas, 48,36\% afirmaram sempre realizar o pós-venda, $35,25 \%$ responderam realizar a prática somente às vezes, e, dentre as empresas que não praticam o pós-venda a representatividade foi de 16,39\% das entrevistadas, dessas $65 \%$ atuam no setor de serviço.

Entre as empresas que fazem o pós-vendas, as notas do quão importante elas consideram essas ações variaram de quatro a dez, sendo seguida a mesma escala de zero a dez anteriormente citada. Observouse que a maioria dos entrevistados atribuiu a nota $10(43,88 \%)$ e $8(23,47 \%)$, demonstrando considerar o pós-venda como muito importante. As ações mais usuais pelas empresas para a aplicação dessa estratégia e demais informações estão apresentadas na Tabela 6.

\begin{tabular}{c|c|c|c|c|c}
\hline Perguntas & \multicolumn{5}{|c}{ Respostas } \\
\hline $\begin{array}{c}\text { Ações de pós- } \\
\text { venda mais } \\
\text { utilizadas }\end{array}$ & $\begin{array}{c}\text { Mesclam estratégias } \\
(61,05 \%)\end{array}$ & $\begin{array}{c}\text { Satisfação do } \\
\text { cliente } \\
(24,21 \%)\end{array}$ & $\begin{array}{c}\text { Oferecimento de } \\
\text { garantia } \\
(6,32 \%)\end{array}$ & $\begin{array}{c}\text { Divulgação de } \\
\text { novos produtos } \\
(4,21 \%)\end{array}$ & $\begin{array}{c}\text { Suporte } \\
\text { técnico } \\
(2,10 \%)\end{array}$ \\
\hline $\begin{array}{c}\text { Quanto tempo } \\
\text { após a venda é } \\
\text { realizado o pós- } \\
\text { venda? }\end{array}$ & $\begin{array}{c}\text { Após a entrega/uso } \\
\text { do produto/serviço } \\
(43,16 \%)\end{array}$ & $\begin{array}{c}\text { Logo após a } \\
\text { venda } \\
(32,63 \%)\end{array}$ & $\begin{array}{c}\text { Quinze dias após } \\
\text { a entrega/uso do } \\
\text { produto/serviço } \\
(10,53 \%)\end{array}$ & $\begin{array}{c}\text { Trinta dias após a } \\
\text { entrega/uso do } \\
\text { produto } / \text { serviço } \\
(8,42 \%)\end{array}$ & $\begin{array}{c}\text { Períodos } \\
\text { mais longos } \\
(4,21 \%)\end{array}$ \\
\hline $\begin{array}{c}\text { Ações após } \\
\text { realizar o pós- } \\
\text { venda }\end{array}$ & $\begin{array}{c}\text { Atende a todas as } \\
\text { sugestões ou } \\
\text { reclamações } \\
(75,51 \%)\end{array}$ & $\begin{array}{c}\text { Atende parcialmente as sugestões } \\
\text { ou reclamações } \\
(22,45 \%)\end{array}$ & $\begin{array}{c}\text { Não atende a nenhuma sugestão } \\
(2,04 \%)\end{array}$ \\
\hline
\end{tabular}

Tabela 6 - Ações de pós-venda realizadas pelas MPEs do Sudoeste do Paraná participantes da pesquisa $-2018$

Fonte: Dados da pesquisa.

Conforme Gobe et al. (2007), pesquisar a satisfação é uma das principais estratégias que as empresas podem utilizar, pois direciona as ações de vendas, aprimora o produto e prevê as oportunidades. Assim, dentre as ações de pós-venda que as empresas utilizam, contatar para saber a satisfação do cliente foi a estratégia que unicamente mais representa as empresas, conforme a Tabela 6. Essa mesma estratégia foi atrelada com 13 diferentes estratégias, e as mais representativas foram: contatar para saber a satisfação do cliente e divulgação de novos produtos (25\%); contatar para saber a satisfação do cliente e suporte técnico (15,38\%); e contatar para saber a satisfação do cliente e garantia (13,46\%). A pesquisa de Coelho et al. (2015) também identificou que a maioria das micros e pequenas empresas buscam saber a satisfação do cliente após a compra.

Ainda de acordo com dados da Tabela 6 , nota-se que as empresas buscam logo após a venda ou entrega do produto e serviço realizarem o pós-venda, e grande parte busca atender as sugestões e/ou verificar as reclamações dos clientes.

Percebeu-se, ainda, que o pós-venda, embora seja uma prática entendida como importante e realizada pela maioria, ainda não está sendo utilizado com todo o seu potencial. A fidelização dos clientes no pós-venda é uma técnica muito importante para o fortalecimento e permanência da empresa no mercado, mas que vem sendo pouco aplicada pelos estabelecimentos. Essa dificuldade pode estar atrelada à falta de conhecimento sobre os clientes, pois houve uma quantidade significativa de empresas que relataram não utilizarem a segmentação do público-alvo com relação ao perfil psicográfico e renda de seus clientes. 


\section{Considerações finais}

A gestão comercial das empresas possibilita a criação de estratégias eficazes para a inserção e a permanência da mesma em um mercado altamente competitivo. Portanto, o objetivo deste estudo foi verificar se as empresas de pequeno porte do Sudoeste do Paraná aplicam ferramentas estratégicas de gestão comercial.

Tais estratégias foram subdividas em três grandes áreas: a pré-venda, venda e o pós-venda. Para identificação da aplicação dessas estratégias por parte das empresas foi elaborado e aplicado um questionário que indagava sobre as estratégias utilizadas nas etapas de vendas.

As principais conclusões sobre o pré-venda concentraram-se nas estratégias de divulgação e propaganda das empresas. Percebeu-se pelas respostas que as mesmas utilizam alguns meios de ações disponíveis de pré-venda, em que o mais comumente utilizado foi a propaganda, e, dentre as estratégias de propaganda, destacou-se a rede social como a mais citada na hora de divulgar os produtos e serviços ofertados. Contudo, a alta diversificação dos canais de comunicação sem conhecimento específico do cliente dos seus estabelecimentos, em que mais da metade não realiza classificação por renda e nem pelo perfil psicográfico, dificulta a definição de um canal claro de comunicação com os mesmos. Com isso, a utilização de diversos canais de comunicação pode tornar o custo de marketing elevado, sem conseguir atingir seu público-alvo e o objetivo definido.

Com relação à etapa de venda, as empresas utilizam diferentes tipos de estratégias para calcular o preço dos seus produtos ou serviços, sendo as mais lembradas na resposta aquelas que relacionavam o custo e a qualidade. Dessa forma, as empresas também procuram mesclar estratégias referentes às sazonalidades encontradas no mercado, bem como nas promoções e a na busca por diferenciação dos seus concorrentes.

$\mathrm{Na}$ etapa do pós-venda, percebeu-se que a estratégia para identificar a satisfação dos clientes é a mais utilizada. Essa técnica quando empregada de forma eficaz possibilita às empresas solucionarem o problema de caracterização dos clientes, assim fortalece o seu vínculo com os mesmos e viabiliza a criação de estratégias promocionais condizentes com o público-alvo.

De forma geral, conclui-se que as micro e pequenas empresas, bem como os empreendedores individuais do Sudoeste do Paraná utilizam diferentes estratégias em relação à venda, sendo possível inferir que existe uma razoável percepção e aplicabilidade das ferramentas estratégicas de gestão comercial. Porém, o pré-venda e o pós-venda precisam ser reforçados, principalmente na caracterização dos clientes e na aplicação de estratégias para garantir a satisfação dos mesmos, e consequentemente auxiliar no aumento de receita.

Por fim, observa-se que as principais dificuldades encontradas durante a elaboração deste artigo foram referentes às fontes de pesquisa em estudos empíricos, havendo uma lacuna ainda a ser explorada pelos pesquisadores na área. Ademais, sugere-se como estudos futuros a aplicação de questões que investiguem também as opiniões e percepções dos empresários sobre a eficácia das estratégias de gestão comercial. Nesse ponto, talvez, dever-se-ia realizar um estudo de caso em alguns setores para uma análise mais aprofundada, visando verificar a eficácia da segmentação do público-alvo e os seus benefícios para as MPEs. E, não menos importante, avaliar também a opinião dos clientes a fim de contrastar com os resultados aqui explicitados.

\section{Nota}

${ }^{1}$ O Programa Bom Negócio Paraná é um projeto de extensão presente em todo o estado do Paraná. Na região Sudoeste paranaense o curso é ofertado pela Universidade Estadual do Oeste do Paraná - Campus de Francisco Beltrão, em parceria com o Governo do Estado do Paraná. Seu objetivo é ofertar capacitação gratuita em gestão empresarial aos empresários de micro e pequenas empresas, microempreendedores individuais, além de futuros empresários. O curso ao todo tem 66 horas e compreende cinco módulos, a saber: gestão de negócios, gestão comercial, gestão financeira, gestão de pessoas e gestão estratégica. 


\section{Referências}

ASSIS, Fernanda de. Comportamento do consumidor. 74 f. Monografia (MBA - Gestão e Estratégia Empresarial). Centro Universitário Filadélfia. Londrina, 2011. Disponível em: < http://web.unifil.br/pergamum/vinculos/000004/0000043D.pdf>. Acesso em: 8 dez. 2018.

BRASIL, LEI COMPLEMENTAR N¹54, DE 18 ABRIL DE 2016. Brasília, 2018. Disponível em: < http://www.planalto.gov.br/ccivil 03/Leis/LCP/Lcp154.htm>. Acesso em 03 dez. 2018.

CHURCHILL JÚNIOR, Gilbert A.; PETER, J. Paul. Marketing: criando valor para os clientes. 3. ed. São Paulo: Saraiva, 2012

COBRA, Marcos. Administração de Marketing no Brasil. 4. ed. Rio de Janeiro: Elsevier, 2014.

COELHO, Ricardo Limongi França et al. Gestão do marketing em micro e pequenas empresas. Revista de empreendedorismo e gestão de pequenas empresas. V. v.4, n.2, 2015. Disponível em: < http://www.regepe.org.br/regepe/article/view/197 >. Acesso em: 25 set. 2018.

CONFEDERAÇÃO NACIONAL DE DIRIGENTES LOGISTAS - CNDL; SERVIÇO DE PROTEÇÃO AO CONSUMIDOR - SPCBRASIL. Perfil das Micro e Pequenas Empresas Brasileiras. 2015.2 Disponível em: <https://www.spcbrasil.org.br/uploads/st_imprensa/relatorio_perfil_mpe1.pdf>. Acesso em: 28 jul 2018.

CÔNSOLI, Matheus Alberto; CASTRO, Luciano Thomé; NEVES, Marcos Fava. Vendas: técnicas para encantar seus clientes. Porto Alegre: Bookman, 2007.

COSTA, Antonio Tavares. Empreendedorismo como ferramenta de desenvolvimento econômico e geração de emprego e renda: elaboração de metodologia para criação de micro e pequenas empresas. Cadernos de Gestão e Empreendedorismo, v.4, n.3, 2016. Disponível em: < http://periodicos.uff.br/cge/article/view/12700 >. Acesso em: 8 dez. 2018.

DATASEBRAE. Pesquisa Perfil da ME e da EPP. Julho 2017. Disponível em: <http://datasebrae.com.br/perfil-dos-pequenos-negocios/>. Acesso em: 30 jul. 2018.

GOBE, Antonio Carlos et al. Administração de Vendas. 2. ed. São Paulo: Saraiva, 2007.

INSTITUTO BRASILEIRO DE GEOGRAFIA E ESTATÍSTICA - IBGE. Projeção da população do Brasil e das unidades de Federação. Disponível em: < https://www.ibge.gov.br/apps/populacao/projecao/>. Acesso em: 8 dez. 2018.

KERIN, Roger A, et al. Marketing. 8 ed. São Paulo: Mc-Graw-Hill, 2007.

KOTLER, Philip; ARMSTRONG, Gary. Princípios de marketing. 15 ed. São Paulo: Pearson Education do Brasil, 2015.

KOTLER, Philip.; KELLER, Kevin Lane. Administração de Marketing. 12. ed. São Paulo: Prentice Hall, 2005.

LAS CASAS, Alexandre Luzzi. Marketing de serviços. 4. ed. São Paulo: Atlas, 2006. a. 
LAS CASAS, Alexandre Luzzi. Marketing de varejo. 4. ed. São Paulo: Atlas, 2006. b.

MATTAR, Fauze. N.; Pesquisa de marketing. 3.ed. São Paulo: Atlas, 2001.

MENDES, Judas Tadeu Gracci. Bom Negócio Paraná. 6. ed. Curitiba: Estação Business School, 2017.

OLIVEIRA, Marta Olivia Rovedder de. et al. Análise qualitativa dos artigos científicos da área de marketing publicados no Brasil: as pesquisas Survey na década de 2000. Revista eletrônica de Administração, $\quad$ v.23, $\quad 2017.1, \quad$ Disponível $\quad$ em: $<$ https://seer.ufrgs.br/read/article/view/55683/41559>. Acesso em 8 dez. 2018.

ONWUEGBUZIE, Anthony J.; LEECH, Nancy L. Sampling. Designs in Qualitative Research: Making the Sampling Process More Public. The Qualitative Report,v.12, n. 2, 2007. Disponível em:< https: / nsuworks.nova.edu/cgi/viewcontent.cgi?article $=1636 \&$ context=tqr $/>$. Acesso em: $8 \mathrm{dez}$. 2018.

PERIN, Marcelo Gatterman et al. Pesquisa Survey em artigos de marketing nos ENANPADs da década de 90. Revista interdisciplinar em marketing, v. 1, n.1, 2002. Disponível em: < http://eduem.uem.br/laboratorio/ojs/index.php/rimar/article/view/26257/14070>. Acesso em: 8 dez. 2018.

PORTER, Michael. Estratégia competitiva: técnicas para análise de indústrias e da concorrência. 2. ed. Rio de Janeiro: Elsevier, 2004.

RAMPAZZO, Lino. Metodologia científica: para alunos dos cursos de graduação e pósgraduação. 7 ed. São Paulo: Edições Loyola, 2013.

SANTOS, A. L.; KREIN, José Dari; CALIXTRE, Andre Bojikian. Micro e pequenas empresas: mercado de trabalho e implicações para o desenvolvimento. Rio de Janeiro: Ipea, 2012. Disponível em: <www.ipea.gov.br/agencia/images/stories/PDFs/.../livro_micro_pequenasempresas.pdf $>$. Acesso em: 28 jul 2018.

SEBRAE. Pequenos Negócios em números. Disponível em: <http://www.sebrae.com.br/sites/PortalSebrae/ufs/sp/sebraeaz/pequenos-negocios-emnumeros,12e8794363447510VgnVCM1000004c00210aRCRD>. Acesso 08 dez. 2018.

TEIXEIRA, Rivanda Meira. Gestão de Marketing em Pequenos Empreendimentos Hoteleiros. Revista Turismo em análise. V.15, N. 1, p. 22-41, 2004. Disponível em: <https://www.revistas.usp.br/rta/article/download/63686/66449/>. Acesso em: 25 set. 2018.

VARGAS, Katiuscia Schiemer; TRINDADE, Luiz Antônio Charão; HORBE, Tatiane de Andrade Neves. Tomada de Decisão em Marketing: em estudo dos critérios de escolha dos canais de divulgação. Revista da micro e pequena empresa. V.8, N. 2, p. 72-83, 2014. Disponível em: < http://www.cc.faccamp.br/ojs-2.4.8-2/index.php/RMPE/article/view/650 >. Acesso em: 25 set 2018. 